\title{
Proteomic analysis of a highly metastatic gastric cancer cell line using two-dimensional differential gel electrophoresis
}

\author{
MASAKO TAKIKAWA ${ }^{1}$, YASUTO AKIYAMA ${ }^{1}$, KOUJI MARUYAMA ${ }^{1}$, AYAKO SUZUKI $^{1}$, FENG LIU ${ }^{1}$, \\ SACHIKO TAI ${ }^{1}$, CHIE OHSHITA $^{1}$, YOSHIHIRO KAWAGUCHI ${ }^{1}$, ETSUROU BANDOU ${ }^{2}$, \\ YUTAKA YONEMURA ${ }^{2}$ and KEN YAMAGUCHI ${ }^{2}$ \\ ${ }^{1}$ Immunotherapy Division, Shizuoka Cancer Center Research Institute; ${ }^{2}$ Department of gastric surgery, Shizuoka \\ Cancer Center Hospital, 1007 Shimonagakubo, Nagaizumi-cho, Sunto-gun, Shizuoka 411-8777, Japan
}

Received March 15, 2006; Accepted June 2, 2006

\begin{abstract}
Stomach cancer is still a major cause of death in Asian people despite a complete cure after the resection of early cancers, mainly because peritoneal dissemination is difficult to treat. In the present study, we used two-dimensional differential gel electrophoresis (2-D DIGE) to identify specific proteins differentially expressed between a highly metastatic stomach cancer cell line MKN-45-P and its parental cell line MKN-45. We detected 27 protein spots in at least 2 of 3 experiments which showed statistically significant differences in abundance. All 27 protein spots were identified using matrix-assisted laser desorption/ionization-time of flight (MALDI-TOF) mass spectrometry (MS) and databasesearching software. A proteomic analysis revealed 13 different proteins with some isoforms sharing different biochemical characteristics, and that 8 proteins were up-regulated, and 5 were down-regulated. The 13 proteins were mainly involved in protein synthesis (transfer RNA synthetase), metabolism (flavoprotein subunit, pyruvate kinase, adenylate kinase), receptor and signal transduction (annexins I and A2), the cytoskeleton (keratin 5, cytokeratin 8) and cell cycling (ts11). These results suggested that a proteomic approach including 2-D DIGE would be an efficient way to identify the proteins responsible for specific biological functions. Moreover, these observations might be novel findings leading to the prediction of postoperative peritoneal recurrence.
\end{abstract}

\section{Introduction}

Gastric cancer is still the leading cause of cancer-related deaths in Japan and other Asian countries. Notably, the treatment of peritoneal dissemination as a cancerous recurrence

Correspondence to: Dr Yasuto Akiyama, Immunotherapy Division, Shizuoka Cancer Center, 1007 Shimonagakubo, Nagaizumi-cho, Sunto-gun, Shizuoka 411-8777, Japan

E-mail: y.akiyama@scchr.jp

Key words: gastric cancer, peritoneal dissemination, matrix-assisted laser desorption/ionization-time of flight mass spectrometry, twodimensional differential gel electrophoresis after surgical resection is very difficult. However, if specific markers for predicting peritoneal recurrence were to be identified, peritoneal dissemination could be detected early and perhaps even eradicated. The phenomenon of metastasis to the peritoneum is thought to require the involvement of many different genes in multiple steps (1). Some specific genes including those for adhesion molecules and apoptosisrelated proteins have been reported to be involved in intraperitoneal metastasis (2-4), but the precise mechanism of peritoneal dissemination remains to be clarified.

Genetic analyses of peritoneal dissemination-related gastric cancer cell lines or clinical specimens have been performed using DNA microarray technology $(5,6)$. So far, many gene candidates considered to be involved in peritoneal dissemination have been reported. However, at present there are no genuine candidates for molecules playing a critical role in metastasis to the peritoneum because of the high variability in the results depending on the type of sample.

Two-dimensional differential gel electrophoresis (2-D DIGE) coupled with matrix-assisted laser desorption/ ionization-time of flight (MALDI-TOF) mass spectrometry (MS) has been applied to the analysis of comparative protein expression in different samples in the search for novel biomarkers $(7,8)$. The 2-D DIGE technology is often used for a direct comparison of changes in protein abundance across multiple samples simultaneously on the same gel with a statistical analysis using the DeCyder software. The proteomic approach with 2-D DIGE is less frequently utilized to study gastric cancer $(9,10)$. Jang et al (9) reported changes in protein expression in 18 stomach adenocarcinoma tissues compared with surrounding normal tissues.

In the present study, we focused on the highly metastatic gastric cancer cell line MKN-45-P, derived from MKN-45 cells and compared the protein expression between the metastatic clone and parental cells by using 2D-DIGE coupled with MALDI-TOF M/S. The MKN-45-P cell line was previously cloned in vivo by repeating intraperitoneal metastasis and demonstrated to have marked invasive activity in vitro $(1,4)$. We eventually identified 13 kinds of proteins as being differentially expressed in the highly metastatic clone, MKN-45-P. 


\section{Materials and methods}

Cell culture. The human gastric cancer cell line MKN-45 and a highly metastatic derivative, MKN-45-P, were established previously. Both cell lines were cultured with 5\% FBS/ RPMI-1640 medium.

Protein extraction. When the cells reached $80-90 \%$ confluence, they were harvested using cell dissociation buffer and washed twice with PBS(-). The cell pellets were incubated in a lysis buffer (50 mM Tris- $\mathrm{HCl}, \mathrm{pH} 8.5,7 \mathrm{M}$ urea, $2 \mathrm{M}$ thiourea, and 4\% CHAPS). The samples were sonicated at $4^{\circ} \mathrm{C}$ and centrifuged at $15,000 \mathrm{rpm}$ for $30 \mathrm{~min}$. Then the supernatant containing the cell proteins was collected, and impurities were removed with a 2-D Clean-Up kit (GE Healthcare Amersham Biosciences, Uppsala, Sweden). The $\mathrm{pH}$ of the protein samples was adjusted to 8.0-9.0. The protein concentration was measured with a Quick Start protein assay kit (Bio-Rad Laboratories, Hercules, CA, USA) and adjusted to $5 \mathrm{mg} / \mathrm{ml}$ with lysis buffer.

CyDye labeling of proteins. The proteins were labeled with fluorescent cyanine dyes developed for 2-D DIGE (GE Healthcare Amersham Biosciences) following the manufacturer's directions. Protein samples $(50 \mu \mathrm{g})$ were labeled with $400 \mathrm{pmol}$ of amine reactive cyanine dyes. The internal control mixture was labeled with the fluorescent dye Cy2. The other samples were labeled with $\mathrm{Cy} 3$ or Cy5. The labeling reaction was conducted at $4{ }^{\circ} \mathrm{C}$ in the dark for $30 \mathrm{~min}$. The reaction was quenched with $10 \mathrm{nmol}$ lysine. The samples labeled with each Cy were mixed, and equal volumes of $2 \mathrm{x}$ sample buffer containing $7 \mathrm{M}$ urea, $2 \mathrm{M}$ thiourea, 4\% CHAPS, and 2\% IPG buffer (GE Healthcare Amersham Biosciences), and $2.4 \%$ Destreak reagent (GE Healthcare Amersham Biosciences) were added to the mixture. The volume of the labeled protein mixture was adjusted to $450 \mu 1$ by adding rehydration buffer (GE Healthcare Amersham Biosciences) containing $1 \%$ IPG buffer.

Experimental design. The methodology established by Alban et al was used. MKN-45-derived proteins (50 $\mu \mathrm{g})$ were labeled with $\mathrm{Cy} 3$, and $\mathrm{MKN}-45$-P-derived proteins $(50 \mu \mathrm{g})$ were labeled with Cy5. A mixture of the proteins of both cells (MKN-45+MKN-45-P: $25 \mu \mathrm{g}+25 \mu \mathrm{g}$ ) was labeled with $\mathrm{Cy} 2$. The sample for the identification of proteins was made separately. A protein mixture ( $400 \mu \mathrm{g})$ of MKN-45 and MIN45-P was adjusted to $450 \mu \mathrm{l}$ by adding rehydration buffer (GE Healthcare Amersham Biosciences) containing 1\% IPG buffer. All samples were separated by 2-DE as detailed in the next section (labeled samples: $n=5$, sample for identification: $\mathrm{n}=1$ ). The experiment was independently repeated three times for reproducibility.

Protein separation by 2-DE. All samples were separated by 2-DE. One-dimensional separation was performed according to $\mathrm{pI}$, and two-dimensional separation was done according to molecular weight. The IPG strips $(24 \mathrm{~cm}$ length, $\mathrm{pI}$ range between 3.0 and 11; GE Healthcare Amersham Biosciences) were rehydrated with the CyDye-labeled protein mixture for $12 \mathrm{~h}$ at $20^{\circ} \mathrm{C}$ and $30 \mathrm{~V}$ using the IPGphor system (GE
Healthcare Amersham Biosciences). Isoelectric focusing was performed at a total of $45.5 \mathrm{kVh}$ at $20^{\circ} \mathrm{C}$. The cysteine sulfhydryls were reduced and carbamidomethylated while the proteins were equilibrated in the two-dimensional loading buffer (glycerol, SDS, urea, trace BPB) supplemented with $1 \%$ DTT for $15 \mathrm{~min}$ at room temperature, followed by $2.5 \%$ iodoacetamide in fresh equilibration buffer for an additional $15 \mathrm{~min}$ at room temperature. After equilibration, the IPG gels were applied onto a $24 \mathrm{~cm}$ acrylamide gel (10-12.5\%). SDSPAGE was performed at $2.5 \mathrm{~W} / \mathrm{gel}$ for $30 \mathrm{~min}$ and then at 30 $\mathrm{W} /$ gel (Max. $100 \mathrm{~W}$ ) for $4-5 \mathrm{~h}$ at $15^{\circ} \mathrm{C}$. All electrophoretic procedures were performed in the dark.

Gel imaging. Labeled sample gels were scanned at appropriate wavelengths for Cy2, Cy3 and Cy5 using a Typhoon 9410 (GE Healthcare Amersham Biosciences). Cy2 images were scanned using a 488 -nm laser and a $520-\mathrm{nm}$ band pass (BP) 40 emission filter. Cy3 images were scanned using a 532-nm laser and a 580-nm BP30 emission filter. Cy5 images were scanned using a 633-nm laser and 670-nm BP30 emission filter. The gel for protein identification was fixed in $10 \%$ methanol, $7 \%$ acetic acid for $2 \mathrm{~h}$, and then incubated in Sypro Ruby in the dark overnight. Sypro Ruby was acquired on the same imager using a 457-nm laser and 610-nm BP 30 emission filter. All gels were scanned at a resolution of $100 \mu \mathrm{m}$.

Spot detection and statistical analysis. The spots were detected and quantified with the DIA mode in DeCyder software (GE Healthcare Amersham Biosciences). The estimated number of spots for the detection procedure was set at 4,000. As recommended, an exclusion filter was used to remove spots greater than the parameter to reject dust particles etc. The intensity of the spots in the $\mathrm{Cy} 3$ and $\mathrm{Cy} 5$ image were normalized to that of the Cy2 image in the same gel. Any differences observed between the gels were due to electrophoretic artifacts, and could be compensated for by normalization. Next, the BVA mode in DeCyder software was used to simultaneously match all 15 protein-spot maps from the five gels, and using the $\mathrm{Cy} 3: \mathrm{Cy} 2$ and $\mathrm{Cy} 5: \mathrm{Cy} 2$ DIA ratios, calculated average abundance changes and Student's t-test p-values. Only those spots with over 2-fold changes in volume after normalization between $\mathrm{Cy} 3$ and $\mathrm{Cy} 5$ were defined as spots of interest.

In-gel digestion and peptide purification. DeCyder software was used to record the positions of the spots of interest as a text file, and an automated spot collector, SpotPicker (GE Healthcare Amersham Biosciences), was used to pick the spots. In-gel digestion of the chosen spots was carried out to generate tryptic peptides. Gel pieces were washed three times with $100 \mathrm{mM}$ ammonium bicarbonate $\left(\mathrm{NH}_{4} \mathrm{HCO}_{3}\right)$ for $20 \mathrm{~min}$, dehydrated with acetonitrile (AN) for $10 \mathrm{~min}$, and dried up thoroughly. Mass spectrometry grade trypsin (Promega, Madison, WI, USA) of $125 \mathrm{ng}$ in $0.1 \%$ RapiGest (Waters, Milford, MA, USA)/100 $\mathrm{mM} \mathrm{NH}_{4} \mathrm{HCO}_{3}$ was added to the gel pieces, and incubated at $37^{\circ} \mathrm{C}$ for $1 \mathrm{~h}$. $\mathrm{HCl}$ was added to the protein digested solution, to resolve the RapiGest remaining, and incubated at $37^{\circ} \mathrm{C}$ for $45 \mathrm{~min}$. The supernatants were removed and transferred to separate tubes, and gel pieces were re-extracted twice with $80 \% \mathrm{AN} / 1 \%$ trifluoroacetic acid 
Table I. Proteins identified in the 2-D DIGE analysis.

\begin{tabular}{|c|c|c|c|c|c|c|}
\hline No. & Proteins & Av. Ratio & T-test & Score & $\mathrm{Mr}$ & $\mathrm{pI}$ \\
\hline 1 & Interferon-induced Mx protein & 3.72 & $9.80 \mathrm{E}-11$ & 123 & 75530 & 5.65 \\
\hline 2 & Interferon-induced $\mathrm{Mx}$ protein & 4.55 & $1.50 \mathrm{E}-08$ & 140 & 75530 & 5.65 \\
\hline 3 & Glycyl-tRNA synthetase & 2.30 & $2.10 \mathrm{E}-09$ & 178 & 77463 & 5.88 \\
\hline 4 & Flavoprotein subunit of complex II & 2.23 & 4.10E-07 & 141 & 72645 & 7.06 \\
\hline 5 & Ts11 cell cycle protein & 4.99 & $4.60 \mathrm{E}-07$ & 228 & 62291 & 6.71 \\
\hline 6 & Pyruvate kinase & -2.05 & $2.10 \mathrm{E}-04$ & 174 & 57841 & 7.58 \\
\hline 7 & Pyruvate kinase & -2.02 & $1.30 \mathrm{E}-07$ & 176 & 57841 & 7.58 \\
\hline 8 & Tyrosyl-tRNA synthetase & 2.58 & $1.50 \mathrm{E}-09$ & 198 & 59106 & 6.61 \\
\hline 9 & Keratin 5 & 2.04 & $2.40 \mathrm{E}-06$ & 255 & 62340 & - \\
\hline 10 & Transfer RNA-Trp synthetase & 3.04 & $1.50 \mathrm{E}-07$ & 78 & 53054 & 5.73 \\
\hline 11 & Cytokeratin 8 (279 AA) & -2.08 & $1.20 \mathrm{E}-07$ & 274 & 30840 & 4.91 \\
\hline 12 & Cytokeratin 8 & -2.11 & $1.10 \mathrm{E}-07$ & 127 & 30840 & 4.91 \\
\hline 13 & Cytokeratin 8 (279 AA) & -2.31 & $3.90 \mathrm{E}-06$ & 234 & 30840 & 4.91 \\
\hline 14 & Cytokeratin 8 (279 AA) & -2.04 & $1.90 \mathrm{E}-06$ & 177 & 30840 & 4.91 \\
\hline 15 & Cytokeratin 8 (279 AA) & -2.66 & $3.70 \mathrm{E}-09$ & 205 & 30840 & 4.91 \\
\hline 16 & Dihydrodiol dehydrogenase isoform DD1 & -2.13 & 2.09E-06 & 122 & 34771 & 8.1 \\
\hline 17 & Annexin I & -2.01 & $3.60 \mathrm{E}-04$ & 69 & 35018 & 7.77 \\
\hline 18 & Annexin A2, isoform 2 & -2.02 & $7.70 \mathrm{E}-04$ & 239 & 38552 & 7.57 \\
\hline 19 & Annexin A2, isoform 2 & -2.51 & $2.30 \mathrm{E}-05$ & 277 & 38552 & 7.57 \\
\hline 20 & Annexin A2, isoform 2 & -2.05 & $1.60 \mathrm{E}-05$ & 95 & 38552 & 7.57 \\
\hline 21 & Annexin A2, isoform 2 & -2.01 & $1.90 \mathrm{E}-10$ & 244 & 38594 & 7.57 \\
\hline 22 & Annexin A2, isoform 2 & -2.63 & $2.80 \mathrm{E}-06$ & 240 & 38552 & 7.57 \\
\hline 23 & Annexin A2, isoform 2 & -2.17 & $8.20 \mathrm{E}-09$ & 274 & 38552 & 7.57 \\
\hline 24 & Annexin A2, isoform 2 & -2.14 & $1.60 \mathrm{E}-05$ & 224 & 38552 & 7.57 \\
\hline 25 & Adenylate kinase 2 & 2.05 & $2.00 \mathrm{E}-10$ & 138 & 25598 & - \\
\hline 26 & Carbonic anhydrase II & -2.10 & $8.20 \mathrm{E}-08$ & 161 & 29200 & 6.87 \\
\hline 27 & Cytokeratin 8 (279 AA) & -3.21 & 4.10E-06 & 257 & 30840 & 4.91 \\
\hline
\end{tabular}

The numbers in the table correspond with spot nos. in Fig. 3. Ratio, the difference in protein expression between MKN-45-P and MKN-45; $\mathrm{Mr}$ and $\mathrm{pI}$, molecular weight and isoelectric point, respectively.

(TFA) for $30 \mathrm{~min}$. The extracted solution was vacuum dried in a Speedvac (TOMY, Tokyo, Japan), and peptides were resuspended in $5 \mu \mathrm{l}$ of $0.1 \%$ TFA. C18 silica desalting/ concentration microcolumns (ZipTip; Millipore, Billerica, MA, USA) were used to purify and concentrate peptides before mass spectrometry.

Protein identification. The purified peptides were analyzed by MALDI-TOF MS using a 4700 proteomics analyzer (Applied Biosystems). The peptides were mixed with $\alpha$ cyano-4-hydroxy-trans-cinnamic acid (Sigma, St. Louis, MO, USA) and spotted onto target plates. Peptide mass maps were acquired in the reflectron mode. The background and trypsinderived peaks were subtracted by using the control gel. Ions specific for each sample were then used to interrogate human sequences entered in the NCBInr database using the MASCOT (www.matrixscience.com) database search algorithms. Searches were performed without constraining protein molecular weight or the isoelectric point, and allowed for the carbamidomethylation of cysteine, partial oxidation of methionine residues, and one missed trypsin cleavage. Highest confidence identification has statistically significant search scores.

\section{Results}

Protein expression was compared between a gastric cancer cell line (MKN-45) and a highly metastatic cell line (MKN45-P) using 2D-DIGE technology with a mixed-sample internal standard (Fig. 1). For gel analysis, MKN-45-derived protein and the MKN-45-P-derived protein were labeled with $\mathrm{Cy} 3$ and $\mathrm{Cy} 5$ respectively, and an equal mixture of the protein of MKN-45 and MKN-45-P was labeled with Cy2 (internal control). All fluorescence-labeled proteins were mixed. After 2D gel electrophoresis (2DE), the Cy2, Cy3, and Cy5 channels were individually imaged from five gels using mutually exclusive excitation and emission wavelengths. A two-color merged representative gel image is shown in 


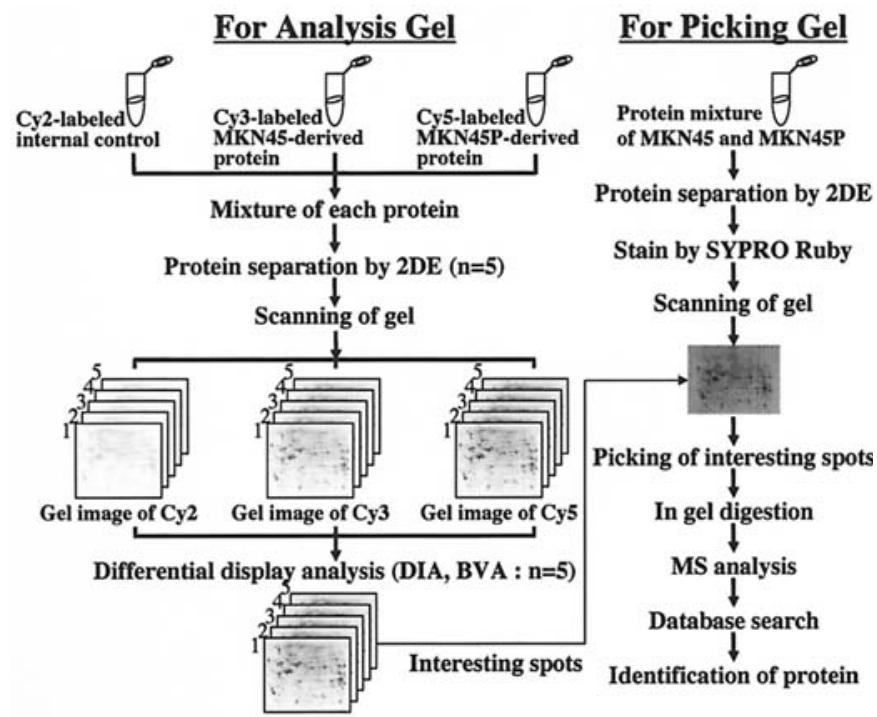

Figure 1. Methods of 2D-DIGE. A mixture of each fluorescent labeled sample was separated by $2 \mathrm{DE}$, and then the gel was scanned at appropriate wavelengths for statistical analysis. As a result of differential display analysis, gel spots of interest were chosen from the picking gel, and proteins were identified using mass spectrometry.

Fig. 2A (Cy3 and Cy5). The green spots indicate that the protein expression was greater in MKN-45 than MKN-45-P. The red spots indicate that the protein expression was less in MKN-45 than MKN-45-P. Next, the images were analyzed using DeCyder software. The number of spots in the five gels was detected with the DIA mode, and those with differential expression were detected with the BVA mode statistically as described above $(n=5, p<0.01)$. Each pair of protein spots generated with $\mathrm{Cy} 3$ and $\mathrm{Cy} 5$ were converted into 3-D representations and displayed to show the relative peak volumes, height and area of each spot. A 3-D simulation allowed an objective inspection of spots corresponding to proteins from $\mathrm{Cy} 3$ and $\mathrm{Cy} 5$. In spot no. 8, the protein expression of MKN-45-P was 2.58-fold that of MKN-45 (Fig. 2B). In spot no. 26, the protein expression of MKN-45-P was $1 / 2.1$ that of MKN-45 (Fig. 2C). The number of spot that changed more than 2-fold was 28 in the first trial, 42 in the second trial, and 42 in the third trial. There were 27 proteins detected more than twice in three attempts.

For the picking gel, an equal mixture of the protein from both cells was separated by $2 \mathrm{DE}$. Then the gel was stained with Sypro Ruby, and scanned at the appropriate wavelength. After gel scanning, the picking gel was matched with the analysis gel. Matched-spots of interest (27 spots) are shown in Fig. 3. Of the 27 spots, 9 were increased and 18 decreased. After the 27 spots were picked by a SpotPicker machine, ingel digestion was carried out. The extracted peptides were purified by ZipTip and analyzed by mass spectrometry. Mass spectra of spots no. 8 and 26 are shown in Fig. 4A and B.

\section{Discussion}

Peritoneal dissemination is suspected to be triggered by multiple genes involved in many aspects of cancer cell invasion and metastasis. However, a proteomic approach investigating the mechanism of peritoneal dissemination using a specific metastatic model has yet to be reported. Our group previously established a highly metastatic cell line, MKN-45-P, with an almost $100 \%$ incidence of peritoneal dissemination, through a serial intraperitoneal passage (1). In the present study, we focused on identifying the proteins expressed differentially in the highly metastatic cell line compared with the parental MKN-45 cell line, in order to analyze the specific parameters which can predict the possibility of peritoneal dissemination. The proteomic analysis revealed 13 different proteins identified from 27 protein spots, 8 of which were up-regulated, and 5 downregulated.

The up-regulated proteins include the IFN-induced $\mathrm{Mx}$ protein, Gly-, Tyr-, Trp-tRNA synthetase, the flavoprotein subunit of complex II, the ts 11 cell cycle protein, keratin 5, and adenylate kinase. The detection of interferon (IFN)induced Mx protein (p78) and tryptophanyl-tRNA synthetase (IFP53) implied that the MKN-45-P cell line was exposed to IFN-like cytokines and regulated to express metastatic biological behavior. With regard to the IFN-inducible protein family, p21 and p27 were reported to be significant prognostic factors in gastric carcinoma patients $(11,12)$. IFP53 was demonstrated to mediate the binding of alpha-IFN activation factors to the gamma-IFN activation site (GAS) (13). There is no significant association of IFN signal activation with a metastatic feature of the MKN-45-P cell line, however, a mechanism stimulating gastric cancer cell adhesion to peritoneal cells might exist, as we reported previously that inflammatory cytokines like IL- 8 or other cytokines enhanced the attachment of MKN-45-P cells (4). There is accumulating evidence that $\mathrm{IL}-8$ is the cytokine involved in tumor cell invasion and metastasis in many types of solid tumors $(14,15)$, and even in gastric cancer patients, IL-8 and VEGF expression in the tumor are good candidates for indicators of poor prognosis (16). Considering that MKN$45-\mathrm{P}$ cells produced more IL- 8 in the supernatant than MKN-45 cells (4), a contribution of IL-8 to the metastatic phenotype of MKN-45-P cells is possible. The correlation of IL-8 to the invasive and metastatic activity of MKN-45-P should be investigated. The expressions of human tyrosyland tryptophanyl-tRNA synthetase were upregulated more than 2-fold. Fragments of the closely related human tyrosyland tryptophanyl-tRNA synthetases were found to be active in angiogenesis signaling pathways, i.e. the fragments of tyrosyl-tRNA synthetase stimulate angiogenesis, whereas those of tryptophanyl-tRNA synthetase inhibit angiogenesis $(17,18)$. There might be a coordinated balance of opposing activities with angiogenesis between the two tRNA synthetases. Unfortunately, the link between the angiogenetic activity and metastatic potential of the MKN-45-P cell line is not clarified. Cell cycle control protein ts 11 encoding asparagine synthetase was found to be up-regulated 5-fold, which is reasonable in terms of accelerating G1 progression resulting in growth stimulation. Additionally, relapsed leukemic cells tend to express high levels of asparagine synthetase and show drug-resistance, especially Lasparaginase-resistance and metastatic characteristics (19). There is accumulating evidence that keratin and cytokeratin are specifically involved in peritoneal recurrence or lymph 


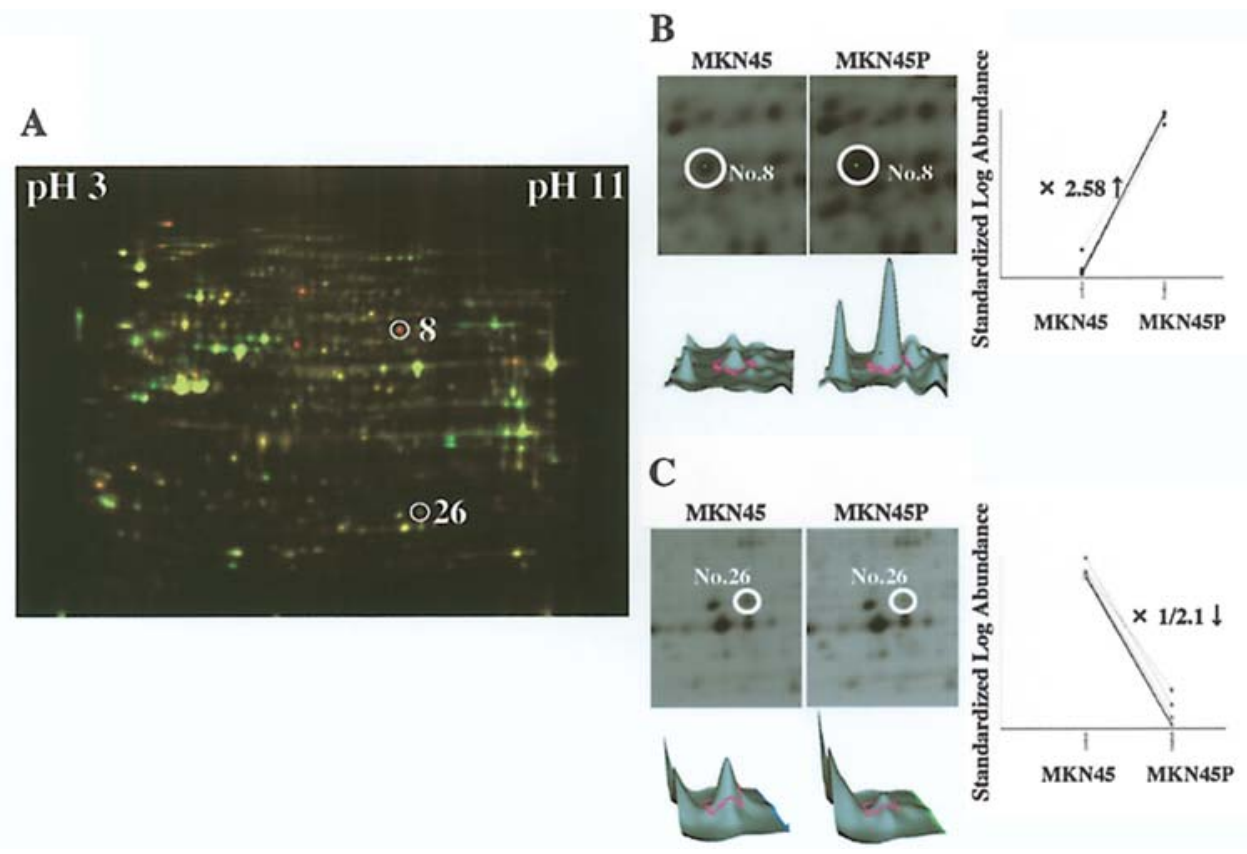

Figure 2. 2D-DIGE gel image and 3D display. (A) Two-color merged 2D-DIGE gel image. The green spots show that the protein expression of MKN-45 was greater than that of MKN-45-P. The red spots show that the protein expression of MKN-45 was less than that of MKN-45-P. The pI ranges from 3 to 11 (left to right). (B and C) The spot where the volume change was extreme between MKN-45 and MKN-45-P was removed, and a graph of volume ratio and a 3D image are shown. Spot no. 8 is shown in B, and spot no. 18 is shown in C.

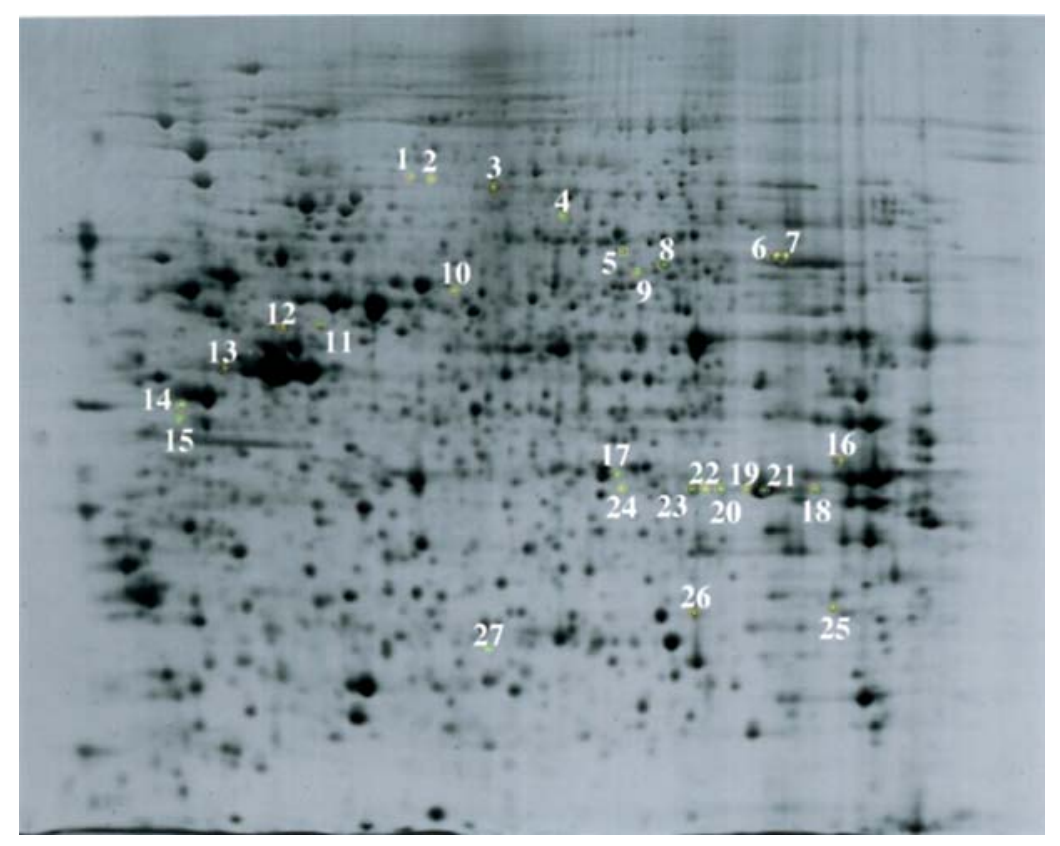

Figure 3. Gel image of Sypro Ruby staining. All annotated spots of the Sypro Ruby staining gel indicated protein spots of interest. There are 27 spots which have $>2$-fold difference between MKN-45 and MKN-45-P ( $<<0.01$, three times by $n=5)$. Nine spots had an increased protein expression in MKN-45-P compared with MKN-45 (No.1-5, 8-10, 25). Eighteen spots had a decreased protein expression in MKN-45-P compared with MKN-45 (Nos. 6, 7, 11-24, 26, 27).

node metastasis in gastric caricinoma patients. Sakakura et al reported that gene expression analysis using a gastric cancer cell line established from malignant ascites revealed upregulation of the keratin 7,8 and 14 genes (6). Additionally, a proteomic approach analyzing protein differential expression between human stomach adenocarcinoma tissue and paired surrounding normal tissue showed that keratin was one of the differentially up-regulated proteins in stomach cancer tissue $(9,10)$. Elevated levels of keratin were considered to be involved in the promotion of adhesion of free cancer cells to the peritoneal epithelium and the formation of cancer nests. Meanwhile, our study revealed that cytokeratin 8 was downregulated in MKN-45-P cells. It was reported that CEA and cytokeratin 20 may be sensitive markers for the detection of micrometastasis to the peritoneum and the prediction of early peritoneal dissemination (20). The association of the downregulation of cytokeratin 8 with metastatic ablity is not clear at present. 
A

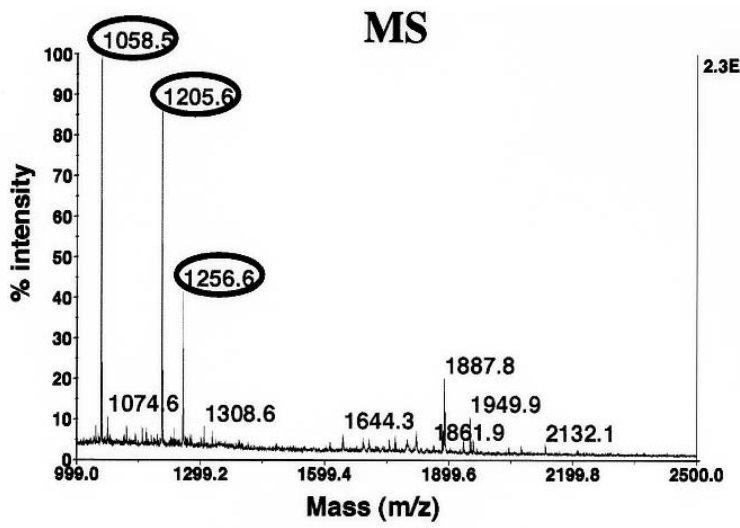

MS/MS analysis

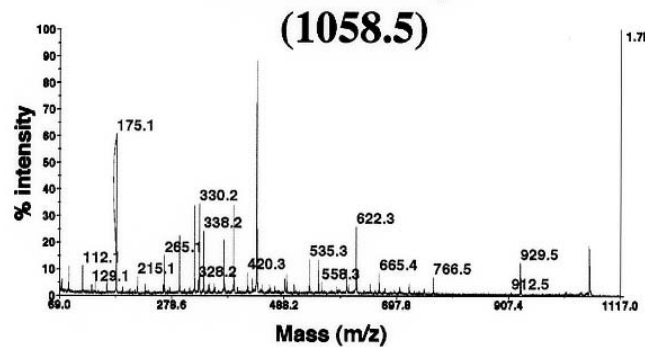

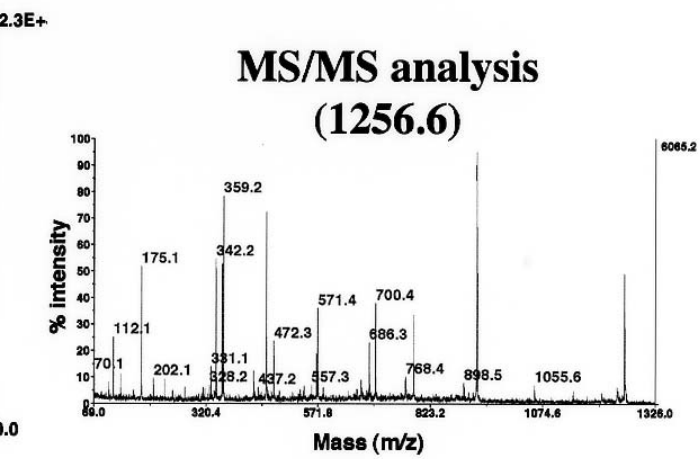

MS/MS analysis

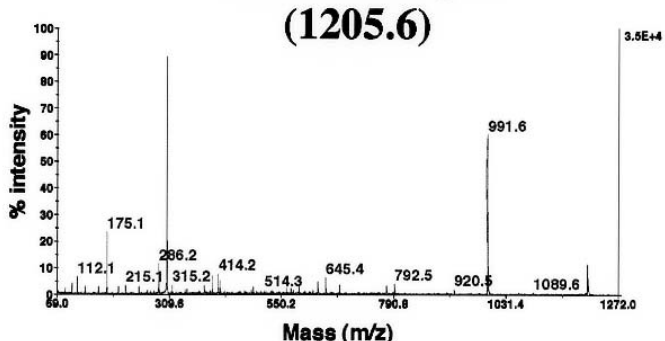

B

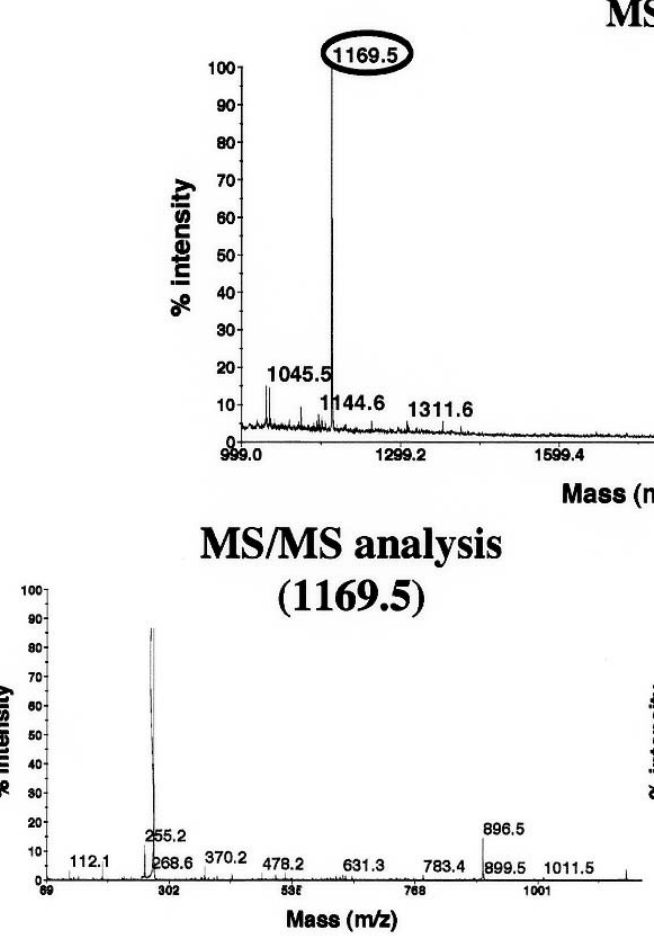

MS
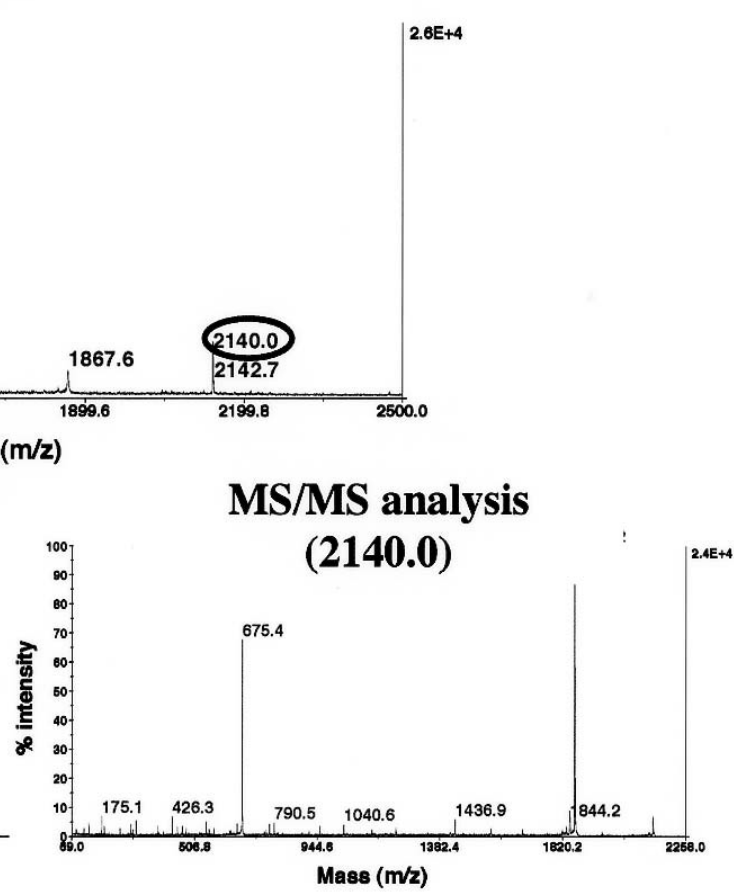

Figure 4. Mass spectrometry of the peptides derived from spots no. 8 and no. 26. Each spot was removed from the gel, and in-gel digestion was performed using trypsin. The digested peptides were purified and concentrated by ZipTip, and then analyzed by mass spectrometry using a 4700 proteomics analyzer. The results of MS and MS/MS analysis are shown. (A) The spectrum of spot no. 8. (B) The spectrum of spot no. 26.

The down-regulated proteins include pyruvate kinase, cytokeratin 8 , didydrodiol dehydrogenase, annexin I, and carbonic anhydrase II. Pyruvate kinase M2 (PK-M2) is a glycolytic isoenzyme predominantly found in proliferating tumor cells. PK-M2 has been utilized as a novel biomarker in gastric cancer, colorectal cancer and melanoma (21). In our study, PK-M2 was found to be down-regulated in MKN-45-P cells. Yoo et al (22) reported that PK-M2 expression is clearly down-regulated in cisplatin-resistant human gastric cancer cell lines, which means that the MKN-45-P cell line shows more malignant and drug-resistant features. Annexins belong to a family of calcium-dependent phospholipidsbinding proteins. The increased expression of annexin I and II is known to be associated with poor prognosis in cases of gastric or pancreatic cancer (23). However, a genetic analysis using DNA microarray demonstrated that annexin A1 
localizing intracellularly is down-regulated in breast cancer or head and neck cancer, which suggests that annexin A1 is an effective differentiation marker for pathological grading (24). Our study showed that annexin A2 was down-regulated in the MKN-45-P cell line. The biological relation of annexin A2 down-regulation with the susceptibility to metastasis to the peritoneum should be investigated. Carbonic anhydrase type II (CAII) is considered to be down-regulated in nonsmall cell lung cancer and advanced colon cancers and might promote tumor cell invasion or metastasis $(25,26)$. The upregulated expression of CAII is also demonstated to be involved in resistance to anticancer drugs (27). It is reasonable that the CAII expression was down-regulated in MKN-45-P cells, however, the specific relation of the down-regulation with the metastatic features of the cells is not clear.

Summarizing the profiling of differentially regulated protein expression according to proteomic analysis of the MKN-45-P cell line, 2 categories of protein profiling exit. One category is the effect of inflammatory cytokines on gastric cancer cells; some cytokines such as interferons or IL-8 stimulated cancer cells, which were promoted to adhere to peritoneal cells and to produce proangiogenetic factors resulting in metastatic capability. The other is the mechanism for a more malignant phenotype of gastric cancer cells; down-regulation of CAII and PK, and up-regulation of ts 11 cell cycle protein, which make gastric cancer cells more invasive and metastatic. In the near future, aiming at the confirmation of these observations, further proteomic analysis using many gastric cancer tissue specimens will be needed.

\section{Acknowledgements}

This study was supported in part by a grant in cooperation of Innovative Technology and Advanced Research in Evolutional Area (CITY AREA) from the Ministry of Education, Culture, Sports, Science and Technology.

\section{References}

1. Yonemura Y, Endo Y, Yamaguchi T, et al: Mechanism of the formation of the peritoneal dissemination in gastric cancer. Int $\mathrm{J}$ Oncol 8: 795-802, 1996.

2. Yawata A, Adachi M, Okuda H, et al: Prolonged cell survival enhances peritoneal dissemination of gastric cancer cells. Oncogene 16: 2681-2686, 1998.

3. Tahara E: Molecular aspects of invasion and metastasis of stomach cancer. Verh Dtsch Ges Pathol 84: 43-49, 2000.

4. Yonemura Y, Endo Y, Nojima N, et al: A possible role of cytokines in the formation of peritoneal dissemination. Int $\mathrm{J}$ Oncol 11: 349-358, 1997.

5. Hippo Y, Yashiro M, Ishii M, et al: Differential gene expression profiles of scirrhous gastric cancer cells with high metastatic potential to peritoneum or lymph nodes. Cancer Res 61: 889-895, 2001.

6. Sakakura C, Hagiwara A, Nakanishi M, et al: Differential gene expression profiles of gastric cancer cells established from primary tumor and malignant ascites. Br J Cancer 87: 1153-1161, 2002.

7. Gharbi S, Gaffney P, Yang A, et al: Evaluation of twodimensional differential gel electrophoresis for proteomic expression analysis of a model breast cancer cell system. Mol Cell Proteomics 1: 91-98, 2002.
8. Alfonso P, Nunez A, Madoz-Gurpide J, Lombardia L, Sanchez L and Casal JI: Proteomic expression analysis of colorectal cancer by two-dimensional differential gel electrophoresis. Proteomics 5: 2602-2611, 2005

9. Jang JS, Cho HY, Lee YJ, Ha WS, Kim HW, et al: The differential proteome profile of stomach cancer: identification of the biomarker candidates. Oncol Res 14: 491-499, 2004.

10. Ryu JW, Kim HJ, Lee YS, et al: The proteomics approach to find biomarkers in gastric cancer. J Korean Med Sci 18: 505-509, 2003.

11. Takano Y, Kato Y, van Diest PJ, Masuda M, Mitomi H and Okayasu I: Cyclin D2 overexpression and lack of p27 correlate positively and cyclin E inversely with a poor prognosis in gastric cancer cases. Am J Pathol 156: 585-594, 2000.

12. Seo YH, Joo YE, Choi SK, Rew JS, Park CS and Kim SJ: Prognostic significance of p21 and p53 expression in gastric cancer. Korean J Intern Med 18: 98-103, 2003.

13. Seegert D, Strehlow I, Klose B, Levy DE, Schindler C and Decker T: A novel interferon-alpha-regulated, DNA-binding protein participates in the regulation of the IFP53/tryptophanyltRNA synthetase gene. J Biol Chem 269: 8590-8595, 1994.

14. Kim SW, Hayashi M, Lo JF, et al: Tid1 negatively regulates the migratory potential of cancer cells by inhibiting the production of interleukin-8. Cancer Res 65: 8784-8791, 2005.

15. Ren Y, Poon RT, Tsui HT, et al: Interleukin-8 serum levels in patients with hepatocellular carcinoma: correlations with clinicopathological features and prognosis. Clin Cancer Res 9: 5996-6001, 2003.

16. Konno H, Ohta M, Baba M, Suzuki S and Nakamura S: The role of circulating IL-8 and VEGF protein in the progression of gastric cancer. Cancer Sci 94: 735-740, 2003.

17. Tzima $E$ and Schimmel P: Inhibition of tumor angiogenesis by a natural fragment of a tRNA synthetase. Trends Biochem Sci 31: 7-10, 2005.

18. Ewalt KL and Schimmel P: Activation of angiogenic signaling pathways by two human tRNA synthetases. Biochemistry 41 : 13344-13349, 2002

19. Aslanian AM, Fletcher BS and Kilberg MS: Asparagine synthetase expression alone is sufficient to induce 1asparaginase resistance in MOLT-4 human leukaemia cells. Biochem J 357: 321-328, 2001

20. Kubota K, Nakanishi H, Hiki N, et al: Quantitative detection of micrometastasis in the lymph nodes of gastric cancer patients with real-time RT-PCR: a comparative study with immunohistochemistry. Int J Cancer 105: 136-143, 2003.

21. Ugurel S, Bell N, Sucker A, Zimpfer A, Rittgen W and Schadendorf D: Tumor type M2 pyruvate kinase (TuM2-PK) as a novel plasma tumor marker in melanoma. Int J Cancer 117: 825-830, 2005.

22. Yoo BC, Ku JL, Hong SH, et al: Decreased pyruvate kinase M2 activity linked to cisplatin resistance in human gastric carcinoma cell lines. Int J Cancer 108: 532-539, 2004.

23. Emoto K, Sawada H, Yamada Y, et al: Annexin II overexpression is correlated with poor prognosis in human gastric carcinoma. Anticancer Res 21: 1339-1345, 2001.

24. Garcia-Pedrero JM, Fernandez MP, Morgan RO, et al: Annexin A1 down-regulation in head and neck cancer is associated with epithelial differentiation status. Am J Pathol 164: 73-79, 2004.

25. Chiang WL, Chu SC, Yang SS, et al: The aberrant expression of cytosolic carbonic anhydrase and its clinical significance in human non-small cell lung cancer. Cancer Lett 188: 199-205, 2002.

26. Bekku S, Mochizuki H, Yamamoto T, Ueno H, Takayama E and Tadakuma T: Expression of carbonic anhydrase I or II and correlation to clinical aspects of colorectal cancer. Hepatogastroenterology 47: 998-1001, 2000.

27. Malloory JC, Crudden G, Oliva A, Saunders C, Stromberg A and Craven RJ: A novel group of genes regulates susceptibility to antineoplastic drugs in highly tumorigenic breast cancer cells. Mol Pharmacol 68: 1747-1756, 2005. 